敌

Engineered Design of SSC Cooling Ponds

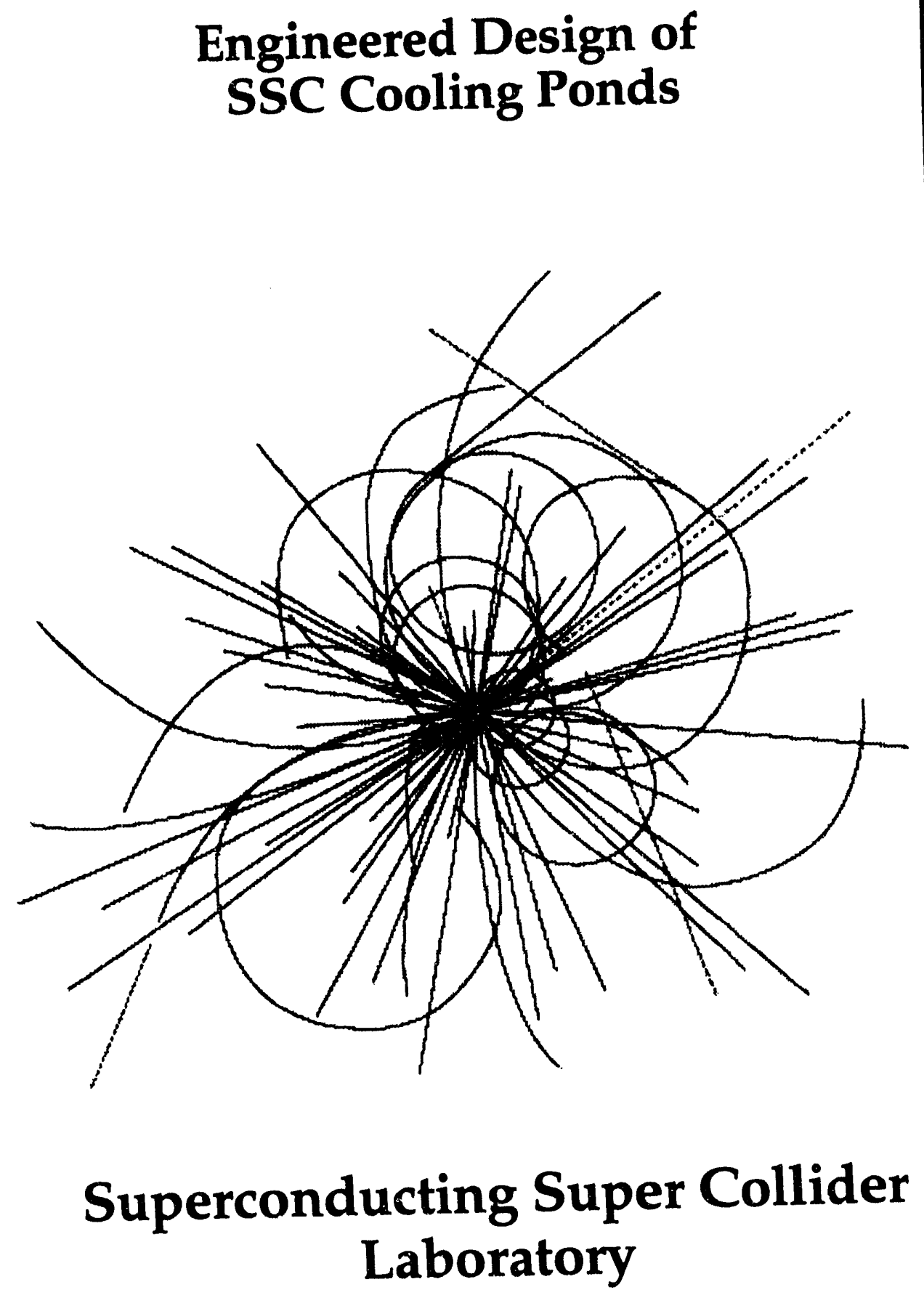

$\cos f-930537--104$

SSCL-Preprint-335

May 1993

Distribution Category: 414

J. Bear

RECEIVED
SEP 011993
OSTI




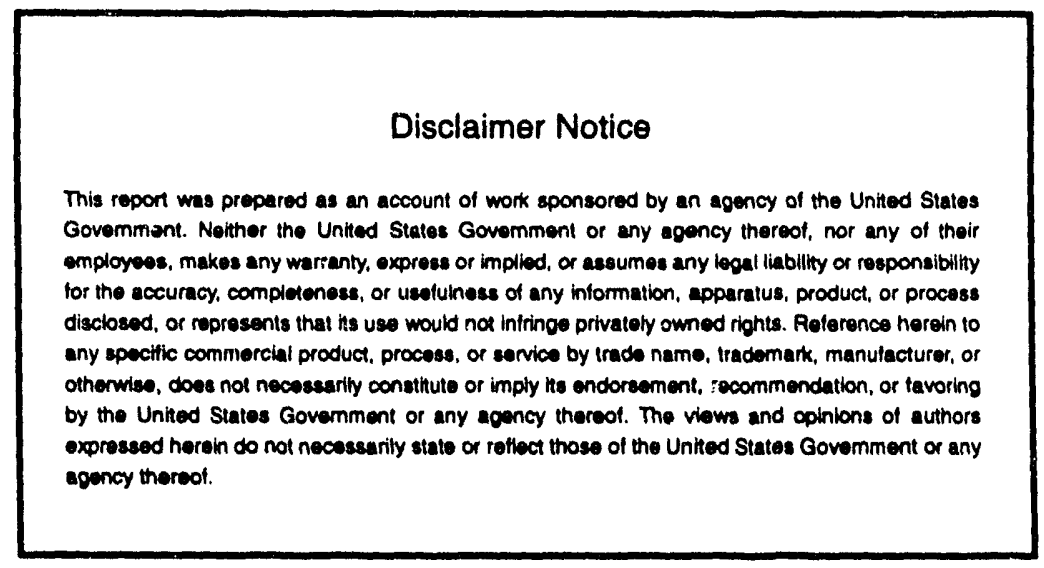

Superconducting Super Collider Laboratory is an equal opportunity employer. 


\title{
Engineered Design of SSC Cooling Ponds ${ }^{*}$
}

\author{
J. Bear \\ Superconducting Super Cllider Laboratory ${ }^{\dagger}$ \\ 2550 Beckleymeade Ave. \\ Dallas, TX 75237
}

May 1993

*Presented at the Fifth Annual International Symposium on the Super Collider, May 6-8, 1993 San Francisco, CA. ${ }^{\dagger}$ Operated by the Universities Research Association, Inc., for the U.S. Department of Energy under Contract No. DE-AC35-89ER40486. 


\title{
ENGINEERED DESIGN OF SSC COOLING PONDS
}

\author{
James E. Bear, P.E. \\ Engineering and Design Group \\ Conventional Construction Division \\ Superconducting Super Collider Laboratory* \\ 2550 Beckleymeade Avenue \\ Dallas, Texas 75237
}

\section{INTRODUCTION}

The cooling requirements of the SSC are significant and adequate cooling water systems to meet these requirements are critical to the project's successful operation. The use of adequately designed cooling ponds will provide reliable cooling for operation while also meeting environmental goals of the project to maintain streamflow and flood peaks to preconstruction levels as well as other streamflow and water quality requirements of the Texas Water Commission and the Environmental Protection Agency.

\section{MECHANISMS OF POND SURFACE HEAT TRANSFER}

Any body of water can gain or lose heat to the atmosphere and the surrounding earth. However, the transfer of heat between the earth and water is limited to conductive transfer only and is insignificant when compared to that which takes place at the air-water interface. All bodies of water receive natural heat input from short-wave solar radiation and long-wave atmospheric radiation and discharge heat to the atmosphere by back radiation, evaporation, and conduction. The various mechanisms by which heat is exchanged between the water and the atmosphere are depicted on Figure 1.

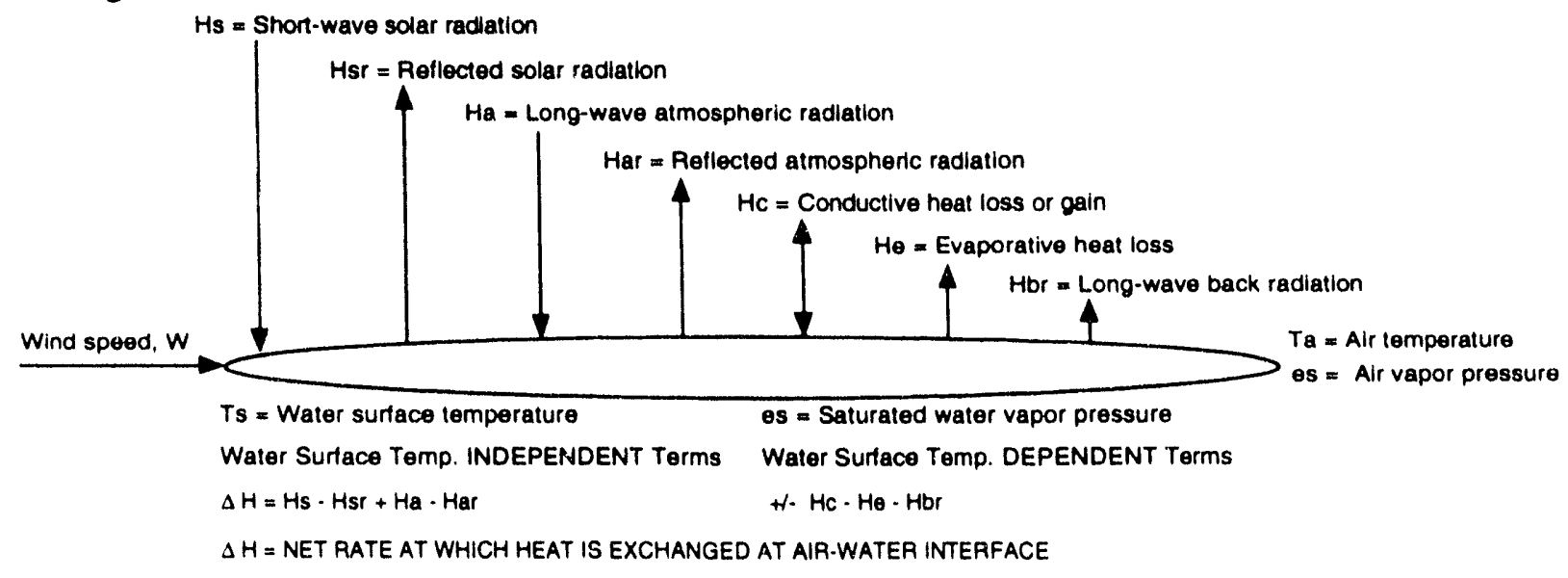

Figure 1. Mechanisms of Heat Transfer Across a Water Surface.

\footnotetext{
* Operated by the Universities Research Association, Inc., for the U. S. Department of Energy under Contract No. DE-AC35-89ER40486.
} 
The four heat transfer mechanisms that are independent of the surface temperature of the water body are described below:

- The incoming short wave solar radiation, $\mathrm{H}(\mathrm{s})$, is the radiant solar energy which passes directly through the atmosphere to the earth from the sun. Its intensity at any location on earth varies with the latitude of the location, time of day, season of the year, and the amount of cloud cover. The amount of short-wave solar radiation reaching the earth's surface can be measured with a pyrheliometer or can be computed based on cloud cover.

- A portion of the incoming solar radiant energy is reflected by the water surface before it can be absorbed by the water. The reflected solar radiation, $\mathrm{H}(\mathrm{sr})$, is a function of the sun's altitude and the amount of cloud cover but can be estimated at $\mathrm{H}(\mathrm{sr})=0.05 \mathrm{xH}(\mathrm{s})$.

- Long-wave atmospheric radiation, $\mathrm{H}(\mathrm{a})$, depends primarily on air temperature and humidity and increases as the moisture content of the air increases. It adds the largest amount of heat to a body of water on warm cloudy days when direct solar radiation decreases to zero. This form of radiation is a complex function consisting of many variables and is largely dependent on the distribution of moisture, temperature, ozone, carbon dioxide, and other materials within the atmosphere. It is generally computed by using empirical formulae.

- A portion of the incoming atmospheric radiant energy is also reflected by the water surface before it can be absorbed by the water. The reflected atmospheric radiation is relatively constant at $\mathrm{H}(\mathrm{ar})=0.03 \mathrm{xH}(\mathrm{a})$.

These four radiation terms $-\mathrm{H}(\mathrm{s}), \mathrm{H}(\mathrm{sr}), \mathrm{H}(\mathrm{a})$, and $\mathrm{H}(\mathrm{ar})$ constitute the net radiation absorbed by the water body and therefore are called total absorbed radiation-- $H(R)$. They can be measured or computed as indicated above and are the four mechanisms independent of the surface temperature of the water body.

The three mechanisms dependent on the surface temperature of the water body are more difficult to determine due to the introduction of another variable. However, these mechanisms, as described below, can be computed using empirical relationships and iterative calculation procedures.

- The conductive heat loss or gain, $\mathrm{H}(\mathrm{c})$, is dependent on the temperature difference between the air and the water at the air-water interface. The rate at which heat is conducted between the water and the air is equal to the product of the difference in temperature between the two media and the heat transfer coefficient. Wind speed also affects the rate of heat loss or gain by conduction as it impacts the heat transfer coefficient.

- The evaporative heat loss from a body of water, $\mathrm{H}(\mathrm{e})$, can be computed by an empirical relationship dependent on wind speed and the difference between the saturated water vapor pressure of the water surface and the water vapor pressure of the air at the interface.

- Back radiation, $\mathrm{H}(\mathrm{br})$, is the ability of a body of water to reject energy to the atmosphere in the form of long-wave radiation since it radiates as an almost perfect black body. The rate at which this heat is lost by a water body is computed from the Stephan-Boltzman fourth power radiation law.

Climatic data requirements used to determine these mechanisms of heat transfer across a water surface include air temperature, relative humidity, wind speed, and solar radiation or cloud cover. The sum of the heat transfer mechanisms at the air-water interface is the net rate at which heat enters or leaves a body of water. For a given set of climatic data, there is a steady-state or thermally balanced condition when the net heat transfer at the air-water interface is zero. The temperature of the water surface for this condition is defined as the natural equilibrium temperature, $\mathrm{E}$.

However, the natural equilibrium temperature is seldom attained in the actual state due to the constantly changing characteristics of the various climatic data. A body of water that has an actual surface water temperature below the natural equilibrium temperature will approach the natural equilibrium temperature by becoming warmer and a body of water having an actual surface water temperature above the natural equilibrium temperatire will approach the natural equilibrium temperature by becoming cooler.

Therefore, the rate of heat exchange for a body of water at its air-water interface is proportional to this difference between the actual water surface temperature and the natural equilibrium temperature. For this reason, a body of water receiving an induced heat load that results in an increase in its water surface temperature, has the capacity to dissipate more heat than a body of water without an induced heat load under the same climatic conditions. Thus, the natural equilibrium 
temperature becomes the reference temperature level for a body of water for a given set of climatic data.

The climatic design requirements for the SSC cooling ponds were established to meet thermal performance requirements $99 \%$ of the time or not be exceeded more than $1 \%$ of the time in a given year. Since the climatic data requirements for cooling pond design include four climatic variables, summer weather data including all four of these parameters for the past 30 years were evaluated to identify months of high natural equilibrium temperatures.

After the eight highest natural equilibrium temperature months were identified in this monthly analysis, daily computations of natural equilibrium temperatures were made for all eight months. A probability analysis of these daily natural equilibrium temperatures was performed to establish the $1 \%$ frequency level. Results of the analysis indicated that the daily natural equilibrium temperature would be between $86^{\circ}$ and $87^{\circ} 1.2 \%$ of the time. Based on this result, the $1 \%$ design level was set at $87^{\circ} \mathrm{F}$.

\section{THERMAL PERFORMANCE OF POND}

The evaluation of the thermal performance of a pond receiving an induced heat load should utilize the time dependent water surface temperature decay equation shown as follows:

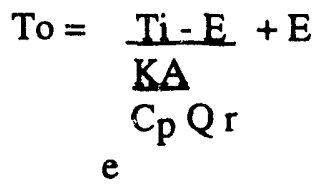

Where: To $=$ Temperature at time $t,\left({ }^{\circ} \mathrm{F}\right)$;

$\mathrm{Ti}=$ Initial temperature at $\mathrm{t}=0,\left({ }^{\circ} \mathrm{F}\right) ; \mathrm{E}=$ Equilibrium temp. $\left({ }^{\circ} \mathrm{F}\right)$;

$\mathrm{K}=$ Heat exchange coefficient, (BTU/Sq Ft/Day/ $/^{\circ} \mathrm{F}$ );

$A=$ Surface area, $(\mathrm{Sq} \mathrm{Ft}) ; \quad r=$ Density of water, $(\mathrm{Lbs} / \mathrm{Cu} \mathrm{Ft})$;

$\mathrm{C}_{\mathrm{p}}=$ Specific heat of water, $\left(\mathrm{BTU} / \mathrm{Lb} /{ }^{\circ} \mathrm{F}\right)$;

$\mathrm{Q}=$ Flow rate $(\mathrm{Cu} F \mathrm{f} / \mathrm{Day})$

While this basic temperature decay equation defines the pond's ability to gain or lose heat through the air-water interface, the complete thermal performance analysis must be based on the pond's ability to maximize surface heat loss as well as its hydrodynamic ability to dampen out thermal transients. Surface heat loss is governed largely by the extent of the pond surface area, but is also a function of the amount of mixing that takes place within the pond. The magnitude of a thermal transient resulting from fluctuating meteorology or induced heat loading is a function of the hydrothermal structure of the pond and its flow circulation patterns which are dependent on location and flow characteristics of intake and discharge facilities as well as any other flow control devices.

The use of computer models to evaluate the thermal performance of power plant cooling water systems has been studied extensively by the Electric Power Research Institute. One of their principal investigators has been Dr. Eric Adams of the R. M. Parsons Laboratory for Water Resources and Hydrodynamics at the Massachusetts Institute of Technology. Dr. Adams was retained as a specialized consultant to review the A-E/CM's methodology of pond design and to assist them in using the MITEMP thermal performance model developed at MIT by Dr. Adams and his colleagues.

The MITEMP model uses a pond classification scheme that includes thermal loading, composite pond number, and horizontal aspect ratio. The SSC cooling ponds are being designed to be classified as the "Shallow Cooling Pond Model with Longitudinal Dispersion." The efficiency of this type of pond is largely dependent on its surface area mobilization and proper pond design should include adequate baffle dikes to guide the circulation of cooling water throughout the pond as well as strategic locations of pond inlet and discharge facilities. Location of the pond inlet to promote surface discharge for the warmer return water and location of the pond discharge to promote subsurface intake of the cooler supply water will also enhance the efficiency of the pond's performance.

The SSC cooling pond design criteria require that an inlet water temperature of $90^{\circ} \mathrm{F}$ be provided for equipment heat exchangers $99 \%$ of the operating time of the machine. This design criteria requires that ponds be designed for a temperature excess of $3^{\circ} \mathrm{F}$ above the $99 \%$ natural equilibrium temperature of $87^{\circ} \mathrm{F}$ for that condition. Heat exchanger inlet (pond discharge) temperatures were also computed for mean monthly conditions and the temperature excess varies from $2^{\circ}$ to $5.9^{\circ} \mathrm{F}$ fur July and January, respectively when the pond discharge temperature varied from 85 to $49.2^{\circ} \mathrm{F}$. 


\section{THE MEB/INJECTOR POND}

The layout of the first SSC pond, the MEB/Injector Pond includes a central baffle dike to guide the circulation path of the cooling water throughout its surface area, and the design will also include some excavation of the pond bottom to eliminate large shallow areas. The proposed design was selected with the aid of costing studies to select the least costly of the alternatives evaluated. The cooling pond water distribution system will serve heat exchangers in the various pump rooms for the LINAC, LEB, MEB, and Test Beam. The pond will provide for $35 \mathrm{MW}$ of cooling per design requirements of not exceeding the $90^{\circ} \mathrm{F}$ pond outflow temperature, and will also provide for $40 \mathrm{MW}$ of cooling about $95 \%$ of the time as well as $47 \mathrm{MW}$ of cooling $90 \%$ of the time without exceeding the $90^{\circ} \mathrm{F}$ temperature limit.

The MEB/Injector Pond will also provide for flood flow attenuation in accordance with environmental goals of the project to provide stormwater detention in project development areas so as to maintain streamflow and flood peaks to pre-construction levels. The effects of the MEB/Injector Pond storage will reduce the 100-year peak flood flow rates from about 1390 cubic feet per second to about 410 cubic feet per second in the unnamed tributary of Chambers Creek downstream of the pond. The volume of flood water will not be reduced but the peak flood flow will be dampened for a longer period of time. This capability of the MEB/Injector Pond will minimize erosion and help maintain more desirable durations of flow rates downstream.

All water consumed in the cooling process by natural and induced evaporation, as well as any miscellaneous leakage and/or additional requirements for water quality maintenance will be replaced by purchased water from downstream water supply reservoirs. All local inflow to the pond must be released so it will not impact downstream water rights, the majority of which are held by the owner of the downstream reservoirs. Therefore, the pond will be maintained at the normal pool level through water purchases as required and any local inflow will pass on downstream.

\section{CONCLUSIONS}

For many years, utilities in Texas have been successfully using power plant cooling ponds and reservoirs to provide reliable cooling water systems while meeting other environmental requirements for these type projects. The SSC can also take advantage of the same qualities with the proper design development, construction, and operation controls of the SSC cooling ponds to insure the successful operation of this important project.

\section{REFERENCES}

1. E. E. Adams, A. L. Godbey, D. R. F. Harleman, and K. R. Helfrich, "Evaluation of Models for Predicting Evaporative Water Loss In Cooling Impoundments," Electric Power Research Institute, Research Project CS-2325, Massachusetts Institute of Technology, Cambridge (1982).

2. J. E. Edinger and J. C. Geyer, "Heat Exchange in the Environment," Cooling Water Studies for the Edison Electric Institute, Research Project RP-49, John Hopkins University, Baltimore (1965). 

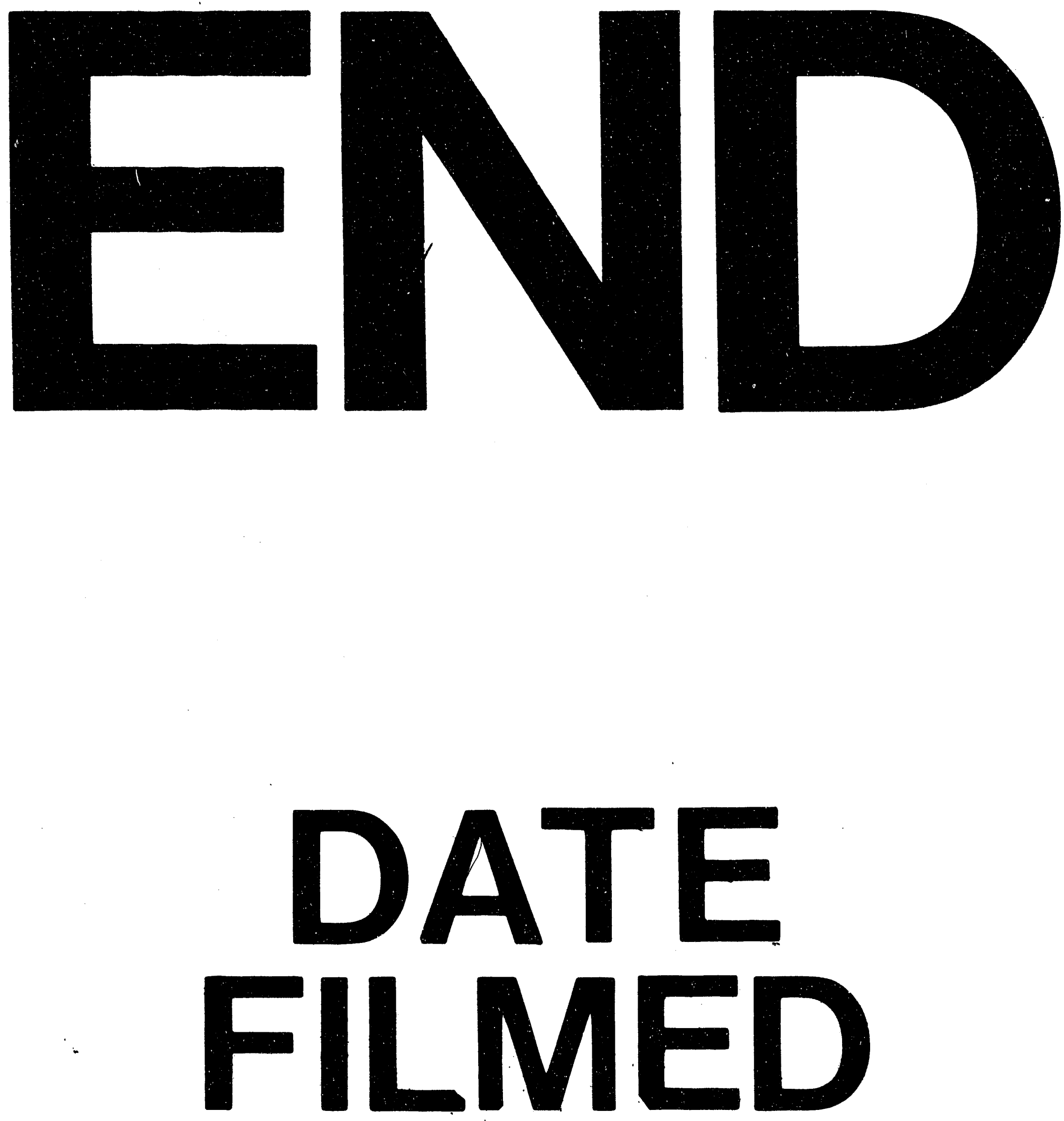

1

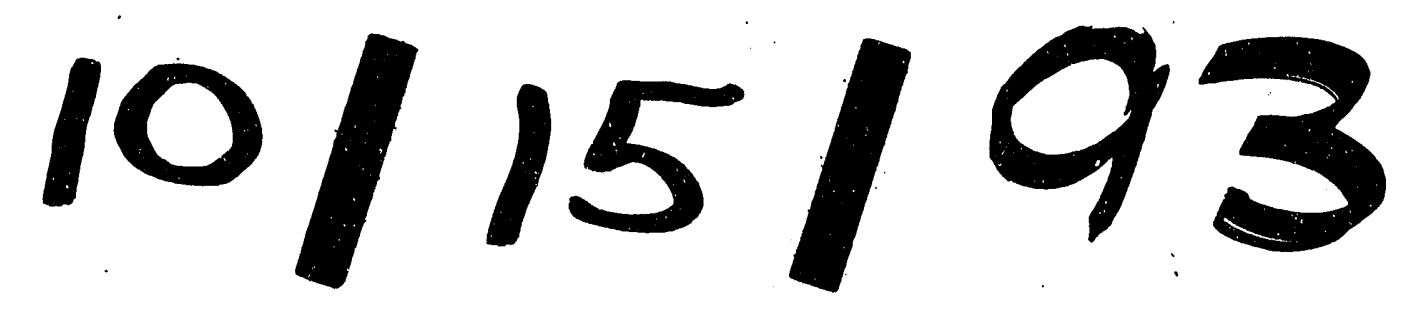


